GU J Sci, Part C, 6(1): 55-65 (2018)

Gazi Üniversitesi
Fen Bilimleri Dergisi
PART C: TASARIM VE TEKNOLOJI
dergipark.gov.tr/http-gujsc-gazi-edu-tr

\title{
Direkt Enjeksiyonlu Bir Dizel Motorunda Atık Zeytinyağı Biyodizelinin Yanma, Performans ve Emisyon Karakteristikleri
}

\author{
Ahmet UYUMAZ ${ }^{1, *}$, Fahrettin BOZ1 , Şükrü Ayhan BAYDIR ${ }^{2}$ \\ ${ }^{I}$ Mehmet Akif Ersoy Üniversitesi, Teknik Bilimler Meslek Yüksekokulu, Otomotiv Teknolojisi Programı,15100, Burdur/Türkiye \\ ${ }^{2}$ Afyon Kocatepe Üniversitesi, Teknoloji Fakültesi, Otomotiv Mühendisliği Bölümü,,03200, Afyonkarahisar/Türkiye
}

$\ddot{O} \mathbf{z}$

Makale Bilgisi

Bașvuru: $30 / 05 / 2017$

Düzeltme: 02/11/2017

Kabul: $20 / 11 / 2017$

\begin{tabular}{l} 
Anahtar Kelimeler \\
\hline Attk zeytinyağl biyodizeli \\
Yanma \\
Motor performansı \\
Egzoz emisyonlart
\end{tabular}

Keywords

Waste olive oil biodiesel Combustion

Engine performance

Exhaust emissions

\begin{abstract}
Bu çalışmada tek silindirli, direkt enjeksiyonlu bir dizel motoru atık zeytinyağından elde edilen biyodizel ve dizel yakıt karışımları ile çalıştırılmış, yanma, motor performansı ve egzoz emisyonları üzerindeki etkileri deneysel olarak araştırılmıştır. Deneyler motorun maksimum tork devri olan $2200 \mathrm{rpm}, 3,75,7,5,11,5,15$ ve $18,75 \mathrm{Nm}$ motor yüklerinde sabit emme havas giriş sıcaklığında gerçekleştirilmiştir. Motor yükü arttıkça silindir basıncı ve 1sı dağılımı atmıştır. Orta ve yüksek motor yüklerinde karışım yakıtlardaki biyodizel miktarı arttıkça maksimum silindir basıncının arttığı görülmüştür. Biyodizelin 1sıl değerinin dizele göre düşük olmasından dolayı tüm motor yüklerinde karışım yakıtlar ile ısıl verim azalmıştır. Maksimum 1sıl verim B10 ve B20 yakıtı ile tam yükte dizele göre sırasıyla \% 7,1 ve \%11,7 azalmıştır. Karışım yakıtlardaki biyodizel miktarı arttıkça karbonmonoksit $(\mathrm{CO})$ ve is emisyonları azalmış, azot oksit $\left(\mathrm{NO}_{\mathrm{x}}\right)$ emisyonu artmıştır. Tam yükte $\mathrm{B} 10$ ve $\mathrm{B} 20$ ile sırasıyla $\mathrm{NO}_{\mathrm{x}} \% 1,5$ ve \%7,5 artı̧̧ göstermiştir. Sonuç olarak dizel motorunda hiçbir değişiklik yapılmadan dizel-atık zeytinyağı biyodizeli karışımlarının kullanılabileceği görülmüştür.
\end{abstract}

\section{Combustion, Performance and Emission Characteristics of Waste Olive Oil Biodiesel in a Direct Injection Diesel Engine}

\begin{abstract}
In this study, a single cylinder, direct injection diesel engine was run with biodiesel from waste olive oil and the effects of diesel-biodiesel fuel blends on combustion, engine performance and exhaust emissions were investigated experimentally. The experiments were performed at maximum engine torque speed $2200 \mathrm{rpm}$, and constant intake air temperature 3.75, 7.5, 11.25, 15 and $18.75 \mathrm{Nm}$ brake torques. In-cylinder pressure and heat release rate increased with the increase of engine load. Maximum in-cylinder pressure increased with the usage of fuel blends at medium and high engine loads. Thermal efficiency decreased with biodiesel fuel blends at all engine loads due to lower heating value of biodiesel than diesel. Maximum thermal efficiency decreased by about $7.1 \%$ ve $11.7 \%$ with B10 and B20 according to diesel at full load respectively. $\mathrm{CO}$ and soot emissions reduced with the increase of biodiesel fraction in fuel blends. However $\mathrm{NO}_{\mathrm{x}}$ increased. $\mathrm{NO}_{\mathrm{x}}$ increased $1.5 \%$ and $7.5 \%$ with $\mathrm{B} 10$ and $\mathrm{B} 20$ compared to diesel at full load respectively. As a result, it was seen that diesel engine can be operated efficiently with diesel-waste cooking oil biodiesel fuel blends without any modification.
\end{abstract}

\section{GİRIŞ (INTRODUCTION)}

Petrol kökenli yakıt rezervlerin tükenmesi, küresel ısınma, çevreye ve doğaya verilen zararın her geçen gün artması araştırmacıları yenilenebilir enerji kaynaklarına yöneltmiştir. Meydana gelen zararın büyük bir kısmı taşıtlarda kullanılan içten yanmalı motorlardan kaynaklanan egzoz emisyonlarıdır [1-8]. Bu noktada özellikle ulaşımda ve taşımacılıkta yaygın bir şekilde kullanılan dizel motorda kullanılabilecek çevreci ve alternatif yakıtlara ihtiyaç duyulmaktadır. Bitkisel ve hayvansal yağlardan elde edilen 
biyodizel hem enerji bakımından dizele yakın özellik göstermekte hem de dizele göre zararlı egzoz emisyonları azaltılabilmektedir. Bunun yanında dizel motorlarda detaylı değişikliğe gidilmeden kolay bir şekilde kullanılabilmektedir [5-12]. Biyodizelin depolama kolaylığı, sülfür içeriğinin az olması, yüksek setan sayısı önemli avantajları arasındadır. Ancak oksijen içeriği nedeni ile $\mathrm{NO}_{\mathrm{x}}$ oluşumu ve dizel yakıtına göre kalorifik enerjisi düşük olduğu için yakıt tüketimi artmakta, elde edilen 1sıl verim azalmaktadır. Dizel yakıtına yakın motor performansı elde edilmekte, $\mathrm{CO}$ ve is emisyonları azaltılabilmektedir. $\mathrm{Bu}$ amaçla sıkıştırma ile ateşlemeli motorlarda farklı motor parametrelerinde biyodizel çalışmalarına ihtiyaç duyulmaktadır. Bu noktada yaygın bir şekilde kullanılan atık zeytinyağı biyodizel üretiminde oldukça önemli bir potansiyele sahiptir [9-17]. Behçet ve arkadaşları [18] atık kızartma yağı-dizel yakıt karışımlarını (B25, B50, B80) bir dizel motorunda test etmiş, performans ve egzoz emisyonları üzerindeki etkilerini incelemişlerdir. Değişken motor devirlerinde yapılan deneylerde dizele göre karışım yakıtlar ile güç ve tork azalmış, yakıt tüketimi artmıştır. Bununla birlikte karışım yakıtların kullanımı ile karbondioksit $\left(\mathrm{CO}_{2}\right)$ ve $\mathrm{CO}$ emisyonlarında azalma, $\mathrm{NO}_{\mathrm{x}}$ emisyonlarında ise artış tespit etmişlerdir. Can [19] atık kızartma yağı biyodizelini hacimsel olarak $\% 5$ ve $\% 10$ oranlarında dizel yakıtı ile karıştırmıştır. Yakıtları tek silindirli direkt enjeksiyonlu bir dizel motorunda $2200 \mathrm{rpm}$ motor devrinde ve farklı yüklerde $(0,48,0,36,0,24,0,12 \mathrm{MPa})$ test etmiştir. Biyodizel-dizel karışım yakıtlarının kullanımı ile özgül yakıt tüketiminde dizel yakıtına göre yaklaşık $\% 4$ artış, 1sıl verimde ise $\% 2,8$ azalma gözlemlemiştir. Biyodizel-dizel karışımları ile $\mathrm{NO}_{\mathrm{x}}$ emisyonlarının \%8,7 arttı̆̆ııı, duman ve hidrokarbon (HC) emisyonlarının azaldığını belirlemiştir. Çelik [1] organik esaslı manganezi pamuk yağı metil esterine $4 \mu \mathrm{mol} / \mathrm{L}, 8 \mu \mathrm{mol} / \mathrm{L}, 12 \mu \mathrm{mol} / \mathrm{L}$ and $16 \mu \mathrm{mol} / \mathrm{L}$ oranlarında ilave etmiş, yanma performansı ve emisyonlar üzerindeki etkilerini incelemiştir. $12 \mu \mathrm{mol} / \mathrm{L}$ karışım oranının en iyi performansı verdiğini ifade etmiştir. Organik esaslı manganez ilavesi ile özgül yakıt tüketiminin ve motor torkunun arttığını belirlemiştir. Dizel yakıtı ile karşılaştırıldığında C0Mn12 yakıtı ile CO, $\mathrm{HC}$ ve is emisyonlarının sırasıyla $\% 11,63, \% 5,02$ ve \% 3,93 azaldığını göstermiştir. Can ve arkadaşları [20] soya yağı biyodizeli-dizel karışımının (B20) ve egzoz gazı dönüşümünün (EGR) yanma, performans ve emisyonlar üzerindeki etkilerini araştırmışlardır. 3,75, 7,5, 11,25, $15 \mathrm{Nm}$ motor yüklerinde ve \% 5, 10, 15 EGR oranlarında yapılan deneylerde \%15 EGR oranında özgül yakıt tüketiminin \%6 arttığını, 1sıl verimin \%3 azaldığını belirlemişlerdir. Aynı zamanda yüksek motor yüklerinde $\mathrm{NO}_{\mathrm{x}}$ ve is emisyonlarının sırasıyla $\% 55$ ve $\% 15$ oranlarında azaldığını tespit etmişlerdir. Bu çalışmada, atık zeytinyağından üretilen biyodizel ve dizel yakıtı karışımlarının (B10, B20) yanma karakteristikleri tek silindirli, direkt enjeksiyonlu, doğal emişli bir dizel motorunda detaylı bir şekilde araştırılmıştır. Deneyler $2200 \mathrm{rpm}$ motor devrinde ve 3,75, 7,5, 11,25, $15,18,75 \mathrm{Nm}$ motor yüklerinde gerçekleştirilmiştir. Silindir basıncı, 1sı dağılımı, tutuşma gecikmesi, yanma süresi ve kümülatif 1 sı dağılımı gibi yanma karakteristikleri, motor performans ve emisyon parametrelerinin değişimleri deneysel olarak araştırılmıştır.

\section{MATERYAL VE METOT (MATERIAL AND METHOD)}

Atık zeytinyağı biyodizelinin yanma, performans ve egzoz emisyonları üzerindeki etkileri deneysel olarak incelenmiştir. Bu amaçla, deney motoru $2200 \mathrm{rpm}$ motor devrinde ve farklı yüklerinde $(3,75,7,5,11,25$, 15 ve $18,75 \mathrm{Nm}$ ) çalıştırılmıştır. Deney düzeneğinin şematik görünümü Şekil 1'de görülmektedir. Deneyler Gazi Üniversitesi Teknoloji Fakültesi Otomotiv Mühendisliği Bölümü İçten Yanmalı Motorlar Laboratuvarında gerçekleştirilmiştir.

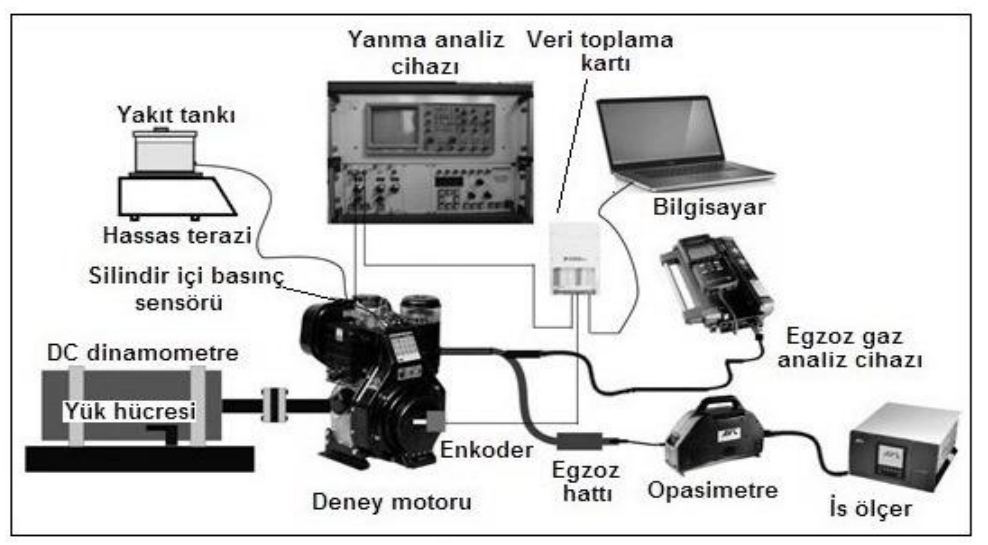


Şekil 1. Deney düzeneğinin şematik görünümü

Deneylerde tek silindirli, direkt enjeksiyonlu, doğal emişli bir dizel motoru kullanılmıştır. Deney motorunun teknik özellikleri Tablo 1'de verilmektedir. Deneyler sabit emme havası giriş $\left(25^{\circ} \mathrm{C}\right)$ ve motor yağ sıcaklıklarında $\left(80^{\circ} \mathrm{C} \pm 1\right)$ gerçekleştirilmiştir. Her deney öncesi motor çalışma sıcaklığına kadar 1sıttılmış ve ölçümler bundan sonra yapılmıştır. Deney motoru Cussons P8160 test yatağına bağlanmış ve doğru akım (DC) dinamometre ile yüklenmiştir. Dinamometre $4000 \mathrm{rpm}$ motor devrinde $10 \mathrm{~kW}$ güç absorbe edebilmektedir. Motor yükü strain gauge yük hücresi ile belirlenebilmektedir. Bununla birlikte motor devrinin ölçülebilmesi için manyetik pick-up sensör kullanılmıştır. Motor yağı ve emme havası giriş sıcaklıkları K tipi termokupllar ile ölçülmüss ve deneyler sırasında sıcaklıklar sabit tutulmuştur.

Tablo 1. Deney motorunun teknik özellikleri

\begin{tabular}{|c|c|c|c|}
\hline Model & & & Antor / 6LD400 \\
\hline Motor tipi & & & Direkt enjeksiyon, do \\
\hline Silindir sayıs1 & & 1 & \\
\hline ÇapxKurs $[\mathrm{mm}]$ & & & $6 \times 68$ \\
\hline Silindir hacmi $\left[\mathrm{cm}^{3}\right]$ & & & 95 \\
\hline S1kıştırma oranı & & & $8: 1$ \\
\hline Maksimum güç [kW] & & & ,4 @ 3000 rpm \\
\hline Maksimum tork $[\mathrm{Nm}]$ & & & 9,6@ 2200 rpm \\
\hline Yanma odas1 geometrisi & & & tipi \\
\hline Yakıt enjeksiyon sistemi & & & F Jerk tipi yakıt pom \\
\hline Enjeksiyon nozulu & & & $.24[\mathrm{~mm}] \mathrm{x} 4$ delik $\mathrm{x}$ \\
\hline Nozul açılma basıncı [bar] & & & 80 \\
\hline Püskürtme zamanlaması[ $\left.{ }^{\circ} \mathrm{KA}\right]$ & & & 44 Üst ölü noktadan ( \\
\hline Supap zamanlamas1 & & & \\
\hline Emme açılma / $\mathrm{E}$ & apanma & & $\begin{array}{l}, 5 \text { ÜÖN'dan önc } \\
\text { oktadan (AÖN) sonn }\end{array}$ \\
\hline Egzoz açılma / E & panma & & 1 AÖN'dan önce \\
\hline $\begin{array}{l}\text { Deney yakıtları dizel ve biyodi } \\
\text { Deneylerde dizel, B10 (\%10 biyod } \\
\text { yakıt kullanılmıştır. Deney yakıtla } \\
\text { yağından transesterifikasyon yönter }\end{array}$ & $\begin{array}{l}\text { (1tlarinın } \\
0 \text { dizel) } \\
\text { ellikleri } \\
\text { de ediln }\end{array}$ & $\begin{array}{l}1 \text { isel ol } \\
\% 20 \mathrm{bi} \\
2 \text { 'de g }\end{array}$ & $\begin{array}{l}\text { larak karıștırılması } \\
\text { yodizel-\% } \% 0 \text { dizel) } \\
\text { örülmektedir. Biyod }\end{array}$ \\
\hline Tablo 2. Deney yakıtlarının özellikt & -27] & & \\
\hline & Dizel & $\mathrm{B} 10$ & $\mathrm{~B} 20$ \\
\hline Distilasyon $\left({ }^{\circ} \mathrm{C}\right)$ & & & \\
\hline IBP & 159,73 & 153,74 & 147,6 \\
\hline FBP & 372,3 & 369 & 364,02 \\
\hline Kükürt (mg/kg) & 7,2 & 6,1 & 4,8 \\
\hline Yakıtın alt 1sıl değeri $[\mathrm{kJ} / \mathrm{kg}]$ & 45343 & - & - \\
\hline Yoğunluk [kg/m³@15 $@$ C] & 826,5 & 831,86 & 838 \\
\hline Kinematik viskozite $\left[\mathrm{mm}^{2} / \mathrm{s}, 40^{\circ} \mathrm{C}\right]$ & 2,78 & 3,177 & 3,318 \\
\hline $\mathrm{Su}, \mathrm{mg} / \mathrm{kg}$ & 23,2 & 88,70 & 204,52 \\
\hline
\end{tabular}

Silindir basıncının ölçülmesi için AVL 8QP500c quartz model su soğutmalı basınç sensörü kullanılmıştır. Silindir basıncı verileri basınç sensöründen alındıktan sonra Cussons P4110 model yanma analiz cihazı ile yükseltilmiş ve analog bilgiler veri toplama kartına gönderilmiştir. National Instruments USB 6259 marka veri toplama kartı ile analog silindir basınç verileri dijital verilere dönüştürülmüştür. Dijital basınç verileri daha sonra bilgisayar kaydedilmiştir. Motor devrinin ve üst ölü nokta (ÜÖN) bilgilerinin tespit edilmesi için deney motorunun krank miline bir turda 360 pals üreten enkoder monte edilmiştir. Krank açısı bilgisi $0,36{ }^{\circ} \mathrm{KA}$ aralıklarla ölçülmüştür. Çevrimsel farklılıkların etkisini azaltmak amacıyla 50 
ardışık çevrimin silindir basınçlarının ortalaması alınmıştır. Yanma analizini gerçekleştirmek için silindir basıncı değerleri kullanılarak 1sı dağılımı, yanma başlangıcı ve yanma süresi gibi yanma karakteristikleri belirlenmiştir. $\mathrm{Bu}$ amaçla Matlab kullanılarak bir program geliştirilmiş ve silindir basıncı verileri işlenmiştir. Tablo 3'de Testo egzoz gaz analiz cihazının özellikleri verilmektedir.

Tablo 3. Testo egzoz gaz analiz cihazının özellikleri

\begin{tabular}{lcc}
\hline \multicolumn{1}{c}{ Yanma ürünleri } & Çalışma aralığ & Doğruluk \\
\hline $\mathrm{O}_{2}$ [vol.\%] & $0-25$ & $\pm 2 \mathrm{mV}$ \\
$\mathrm{CO}[\mathrm{ppm}]$ & $0-10000$ & $5 \mathrm{ppm}(0-99 \mathrm{ppm})$ \\
$\mathrm{CO}_{2}[$ vol.\%] & $0-50$ & $\pm 0.3 \mathrm{vol} \%+1 \mathrm{mV} . \%(0-25)$ vol.\%) \\
$\mathrm{HC}[\%]$ & $0.01-4$ & $(0-25 \mathrm{vol} . \%)$ \\
$\mathrm{NO}_{\mathrm{x}}[\mathrm{ppm}]$ & $0-3000$ & $<400 \mathrm{ppm}(100-4000 \mathrm{ppm})$ \\
\hline
\end{tabular}

Deneylerde is emisyonları teknik özellikleri Tablo 4'de verilen AVL Di-Smoke 4000 is ölçer ile ölçülmüştür.

Tablo 4. AVL Di-Smoke 4000 is ölçerin teknik özellikleri

\begin{tabular}{ccc}
\hline Analiz cihazı & \multicolumn{2}{c}{ AVL DiSmoke 4000} \\
\hline Ölçüm metodu & \multicolumn{2}{c}{ Kısmi akışlı } \\
& Opasite & K değeri \\
Çalışma aralığ & $0-100 \%$ & Doğruluk \\
Doğruluk $\left[\mathrm{m}^{-1}\right]$ & $0-99,99$ & $0,1 \%$ \\
\hline
\end{tabular}

Deneylerde sabit motor devrinde motor yüküne bağlı 1sıl verim ve yanma karakteristikleri gibi değişkenler belirlenmiştir. Isı dağılımı termodinamiğin birinci yasasına bağlı olarak silindir basıncı kullanılarak belirlenmiştir. Isı dağılımı hesaplanırken silindir içi şarj dolgusunun ideal gaz olduğu kabulü yapılmıştır. Bununla birlikte silindirde supaplardan ve segmanlardan gaz kaçaklarının olmadığı kabul edilmiştir [24-27]. Isı dağılımını hesaplamak için eşitlik (1) kullanılmıştır.

$$
\frac{d Q}{d \theta}=\frac{k}{k-1} P \frac{d V}{d \theta}+\frac{1}{k-1} V \frac{d P}{d \theta}+\frac{d Q_{\text {heat }}}{d \theta}
$$

Eşitlik (1)'de $d Q, d Q_{\text {heat }}$ ve $d \theta$ sırasıyla 1sı dağılımı, silindir cidarlarına transfer edilen 1sıyı ve krank açısını göstermektedir. $k$ ise özgül ısıların oranını ifade etmektedir. Yanma analizi için silindir basıncı ve yakıt hat basıncının belirlenmesi önemlidir. Şekil 2-a krank açısına bağlı yakıt hat basıncının değişimini göstermektedir. Silindir basınc1, 1S1 dağılımı ve silindir basıncının birinci türevi Şekil 2-b'de görülmektedir.
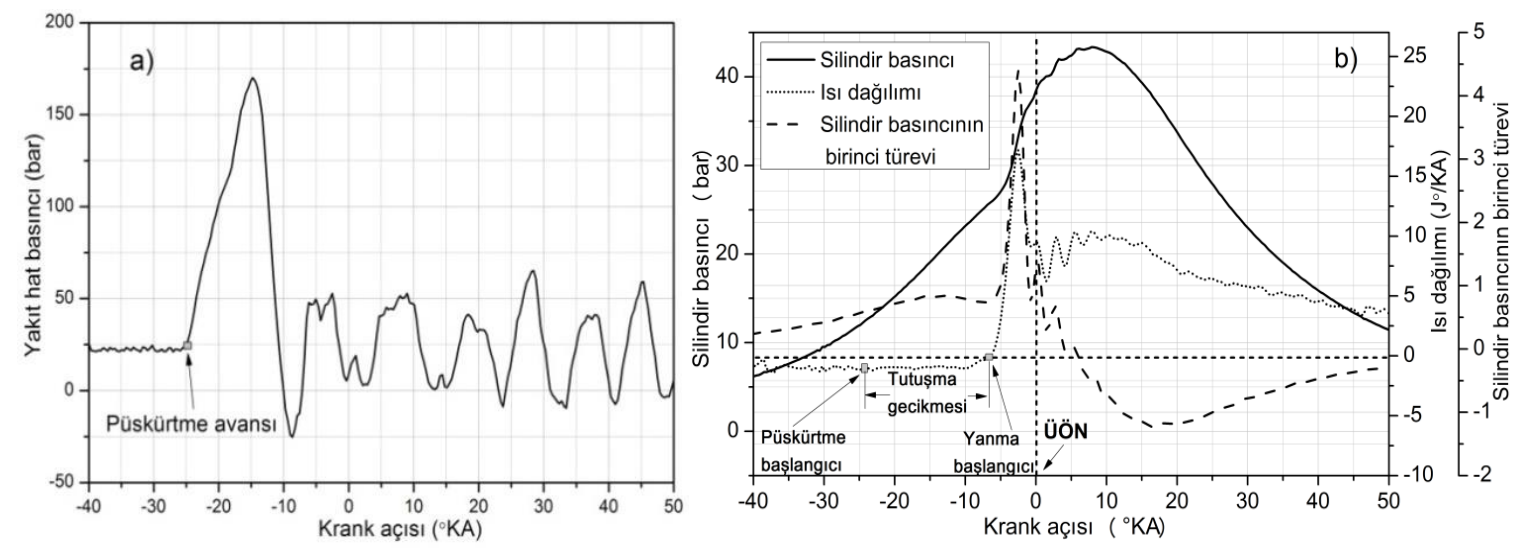
Şekil 2. a) Yakıt hat basıncı b)Silindir basıncı, ısı dağılımı ve silindir basıncının birinci türevi

Yapılan deneylerde yanma başlangıcı krank açısına göre 1sı dağılımının negatif değerden pozitif değere yükseldiği nokta olarak kabul edilmiştir. Püskürtme başlangıcı ile yanma başlangıcı arasındaki süre tutuşma gecikmesini göstermektedir. Yanma sonunun tam olarak belirlenmesi güçtür. Silindirden duvarlara gerçekleşen 1sı transferi ve yanma odasındaki termodinamik şartla değişmektedir. Bu çalışmada yanma sonu karışımın \% 90’ının yanmasını tamamladığı nokta olarak kabul edilmiştir.

\section{DENEY SONUÇLARI (EXPERIMENTAL RESULTS)}

Atık zeytin yağı biyodizelinin dizel motorlarda kullanımı, yanma, performans ve emisyon üzerindeki etkileri detaylı incelenmelidir.
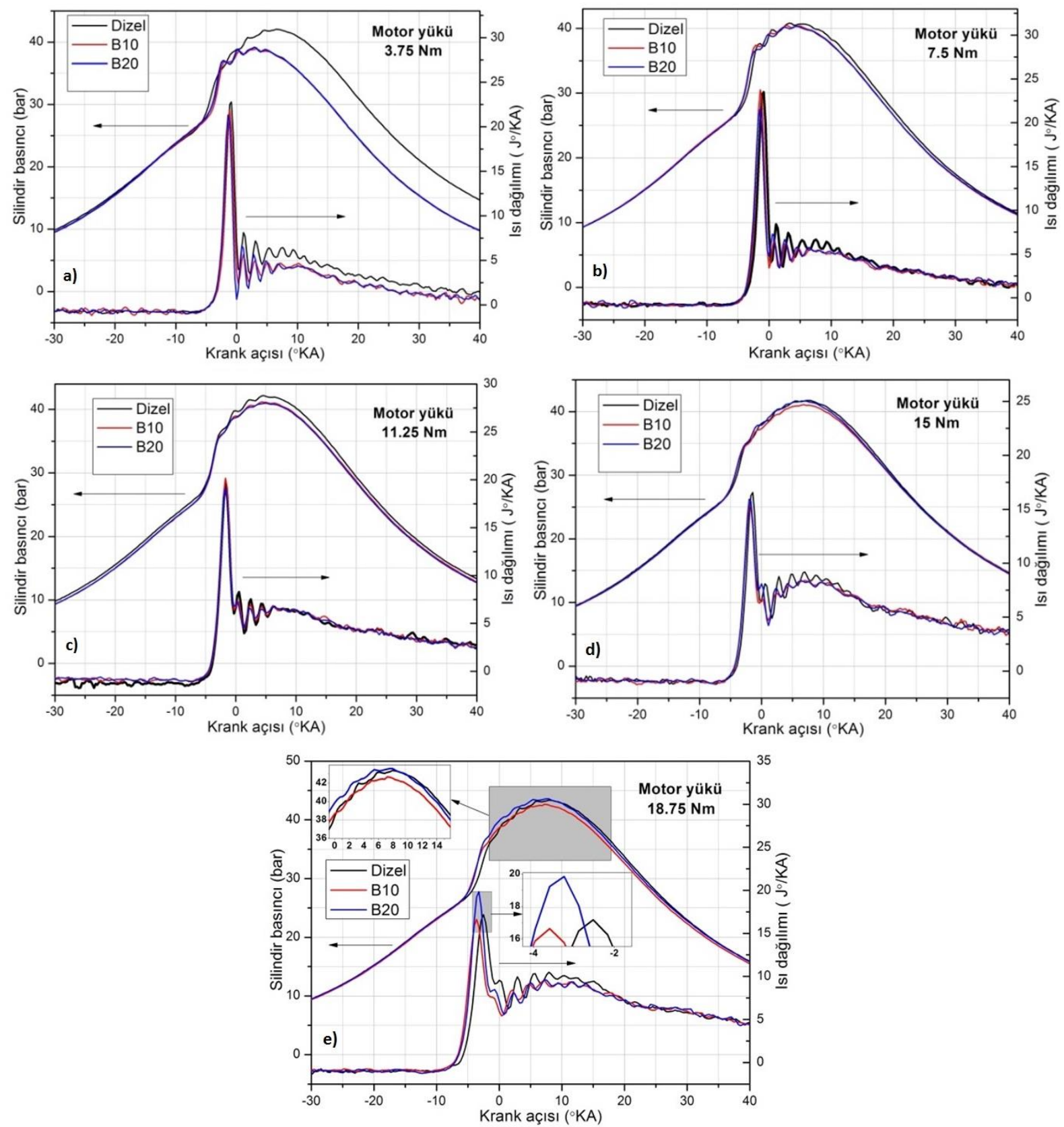

Şekil 3. $\boldsymbol{a}-3,75 \mathrm{Nm}$ motor yükü için silindir basıncı ve ısı dă̆̆llmı b-7,5 Nm motor yükü için silindir basıncı ve ısı dağılımı c-11,25 Nm motor yükü için silindir basıncı ve ısı dă̆ıllımı d-15 Nm motor yükü için silindir basıncı ve ısı dă̆ılımı e-18,75 Nm motor yükü için silindir basıncı ve ısı dağıllımı 
Şekil 3 dizel ve biyodizel yakıt karışımlarının motor yüküne göre silindir basıncı ve 1sı dağılımı üzerindeki etkilerini göstermektedir.Dizel yanmasında ön karışımlı yanma ve difüzyon yanma safhaları görülmektedir. Motor yükü arttıkça 1sı dağılımının ÜÖN'dan öne doğru alındığ1 görülmektedir. Buna benzer şekilde motor torku arttıkça biyodizel ile elde edilen basınç ve 1sı dağılımlarının dizele göre arttı̆̆ görülmektedir. Şekil 3 incelendiğinde düşük yüklerde B10 ve B20 ile elde edilen silindir basınc1 değerlerinin dizelden az olduğu görülmektedir. Fakat şekil 3'te görüldügü gibi tam yükte $(18,75 \mathrm{Nm})$ maksimum silindir basıncı ve 1sı dağılımı B20 yakıtı ile elde edilmiştir. Bununla birlikte motor yükü arttıkça maksimum silindir basıncının daha geç elde edildiğini ifade etmek mümkündür. Özellikle yüksek motor yüklerinde biyodizelin oksijen içeriğinin fazla olması, dizele yakın 1sıl enerjisinin olması açığa çıkan 1S1 enerjisini arttırmaktadır. Düşük yükte B10 ve B20 yakıtları ile bir vuruntu temayülünden bahsetmek mümkündür.3,75 Nm motor yükünde maksimum silindir basıncı ÜÖN yakınlarında elde edilmiş ve maksimum 1sı dağılımı azalmıştır. Motor yükü 7,5 Nm'ye çıkarıldığında karışım yakıtlar ile maksimum silindir basıncı dizele ulaşmakta ve elde edilen basınçlar ÜÖN'yı geçtikten sonra (5-6 KA) elde edilmektedir. Motor yükü daha da arttırıldığında B10 ve B20 yakıtları benzer silindir basıncı değişimi göstermektedir ve 1 ș dağılımları arasında çok fazla fark bulunmamaktadır. $15 \mathrm{Nm}$ yükte B10 ve B20 yakıtları ile vuruntu eğilimi azalmakta B20 yakıtı ile dizele göre daha fazla silindir basıncı elde edilmektedir. Tam yükte maksimum silindir basıncı B20 ile elde edilmiştir. Biyodizelin oksijen içeriği yanmayı iyileştirmekte ve daha fazla basıncın açığa çıktığı görülmektedir. Şekil 4 test yakıtları ile motor yüküne bağlı tutuşma gecikmesi sürelerini göstermektedir. Tutuşma gecikmesi yakıtın setan sayısı, yoğunluğu ve viskozite değerlerine göre değişmektedir. Motor yükü arttıkça tutuşma gecikmesi süreleri kısalmaktadır. Silindir içinde daha fazla karışım kütlesinin yanması silindir sıcaklığını arttırmakta, yanma şartları iyileşmektedir. Bu durum yakıtın daha erken buharlaşması ve tutuşmaya başlayarak yanmasına neden olmaktadır. Sonuçta tutuşma gecikmesi süresi kısalmaktadır. Biyodizel yakıt karışımları ile tutuşma gecikmesi süreleri artmıştır. Biyodizelin ısıl değerinin düşük olması, viskozite ve yoğunluğunun yüksek olması tutuşma gecikmesini arttırmaktadır. Bu noktada biyodizel karışımları içinde en uygun yakıtın B20 olduğunu ifade etmek mümkündür. Daha yüksek setan sayısı ve B20 yakıtındaki daha fazla oksijen içeriği, karışımın reaktivitesi artırarak tutuşma gecikmesini düşürmüştür. Literatüre bakıldığında bir noktadan sonra karışımdaki biyodizel oranının artmasıyla, vizkozite artışının yakıtın atomizasyonunu kötüleştirdiği ve tutuşma gecikmesi süresini uzattığı görülmektedir.

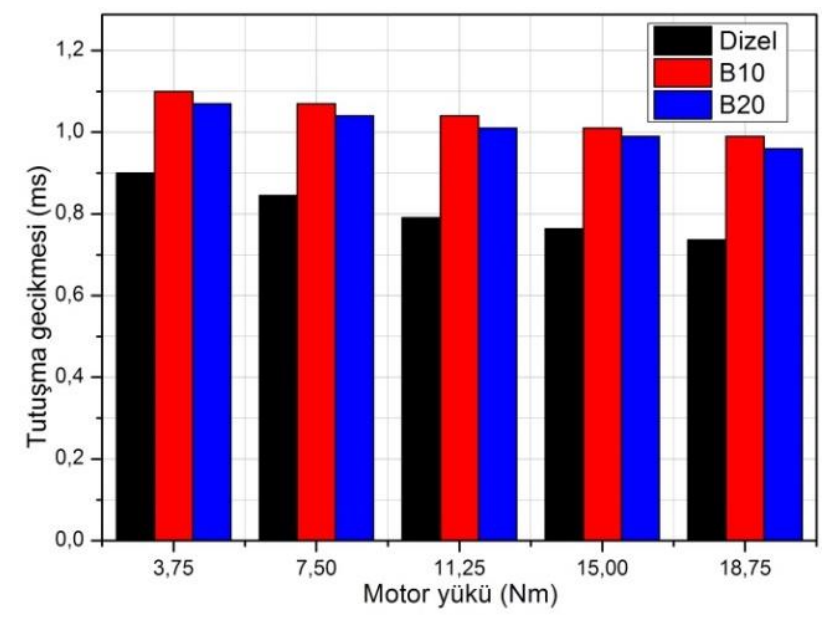

Şekil 4. Tutuşma gecikmesi

Şekil 5'de yanma süresinin motor yüküne göre değişimini görülmektedir. Düşük motor yükünde tüm yakıtlar için yanma süresi krank açısı cinsinden kısadır ve aralarında belirgin bir fark görülmektedir. Ancak yük arttıkça yanma süreleri arasındaki bu fark azalmaktadır. Düşük ve yüksek motor yükleri arasında yanma süresi arasındaki fark artmaktadır. Tüm motor yüklerinde maksimum yanma süresi B20 ile elde edilmiştir. Yüksek yoğunluk ve viskoziteye sahip biyodizelin yanmasını tamamlaması için daha fazla süreye ihtiyaç duyulmaktadır. Yanma odasına çevrimden çevrime alınan karışımın kompozisyonu ve termodinamik haller değişmektedir. Yanmasını tamamlayamamış hidrokarbonlar ve art egzoz gazları bir sonraki çevrime aktarılmaktadır. Bunun sonucunda çevrimsel farklılıklar görülmektedir. Şekil 6'da çevrimsel farklılıkların değişimi görülmektedir. Özellikle düşük motor yüklerinde B10 ve B20 yakıtları 
ile dizele göre daha kontrolsüz bir yanma gerçekleşmektedir. Bunun sonucunda karışım yakıtlar ile çevrimsel farklılıklar artış göstermektedir.

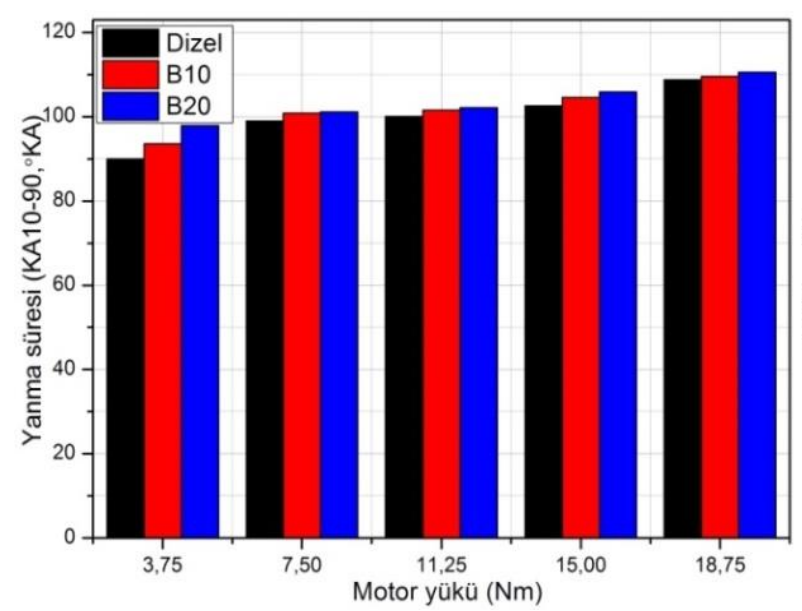

Şekil 5.Yanma süresinin değişimi

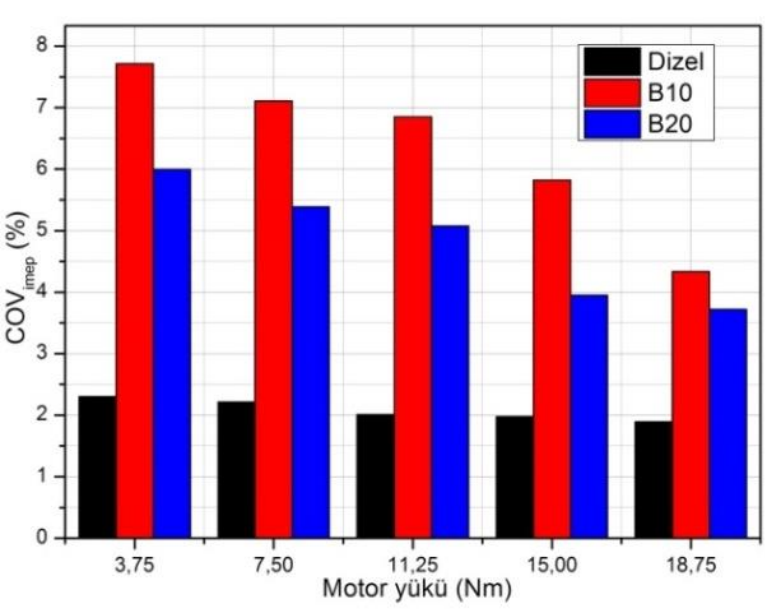

Şekil 6. Çevrimsel farklılıklar

Literatürde çevrimsel farklılıkların \%10'u geçmemesi istenmektedir [22-27]. Şekil 6 incelendiğinde bu tüm motor yüklerinde bu değerin aşılmadığı görülmektedir. Tam yükte B10 ve B20 ile elde edilen $\mathrm{COV}_{\text {imep }}$ değerleri arasındaki fark azalmıştır. Maksimum çevrimsel farklılıklar B10 ve B20 ile 3,75 Nm motor yükünde sırasıyla \%7,71 ve \%5,99 hesaplanmıştır. Yük arttıkça yakıt ile oksijen molekülleri daha kolay buluşma imkanı bulmakta, bunun sonucunda silindir cidar sıcaklığı yükselmektedir Yanmaya daha elverişli bir yanma odası olduğundan daha stabil bir yanma gerçekleşmektedir. Şekil 7'de motor yüküne göre maksimum basınç artış oranının değişimi görülmektedir. 3,75 Nm yükte maksimum basınç artışı dizel ile elde edilmiştir. Yük arttığında tüm yakıtlar için maksimum basınç artışı azalmaktadır. Tüm yüklerde minimum basınç artışı B20 ile elde edilmiştir. Tam yükte dizel, B10 ve B20 ile sırasıyla 3,27, 3,10 ve 3,00 bar/'KA maksimum basınç artış oranı hesaplanmıştır.

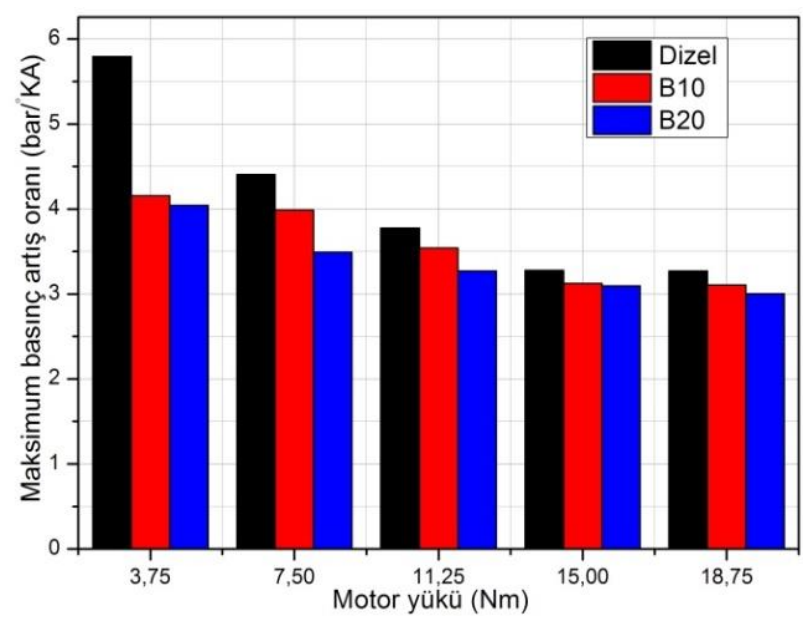

Şekil 7. Maksimum basınç artış oranının motor yüküne göre değişimi

Şekil 8-a ve Şekil 8-b KA50 ve 1sıl verim değerlerinin değişimini göstermektedir. Yüksek 1sıl verim için KA50 ÜÖN'dan hemen sonra elde edilmelidir. Bu noktada KA50 ve hesaplanan 1sil verimler arasinda uyum görülmektedir. Maksimum KA50 tüm yüklerde B20 ile elde edildiğinden minimum 1sıl verim bu test yakıtı ile hesaplanmıştır. Dizelin 1sıl değeri biyodizelden yüksek olduğundan maksimum 1sı1 verim dizel ile elde edilmiştir. Maksimum 1 sıl verim 11,25 Nm yükte dizel, B10 ve B20 ile sirasıyla \%28,3, \% 26,35 ve \%26,09 olarak hesaplanmıştır. Karışımdaki biyodizel oranı arttıkça 1sıl verim azalmaktadır. Tam yükte ise 1s1l verim B10 ve B20 yakıtı ile sırasıyla dizele göre \%7,1 ve \% 11,7 azalmıştır. Yüksek motor yüklerinde yanma odasında oksijen konsantrasyonu azalmakta, yakıtın oksidasyonu kötüleşmektedir. Bununla birlikte birim hacimde silindire kütlece püskürtülen biyodizel yakıt miktarı arttığından aynı gücü 
motorun üretebilmesi için daha fazla yakıt tüketmek zorunda kalmaktadır. Sonuçta 1sıl verim azalmaktadir.

CO yetersiz sıcaklık ve oksijen miktarına bağlı olarak açığa çıkan eksik yanma ürünüdür [22-27]. Yanma odasındaki oksijen konsantrasyonu eksikliği yakıtın oksidasyonunu yavaşlatır ve $\mathrm{CO}$ oluşumu görülür.
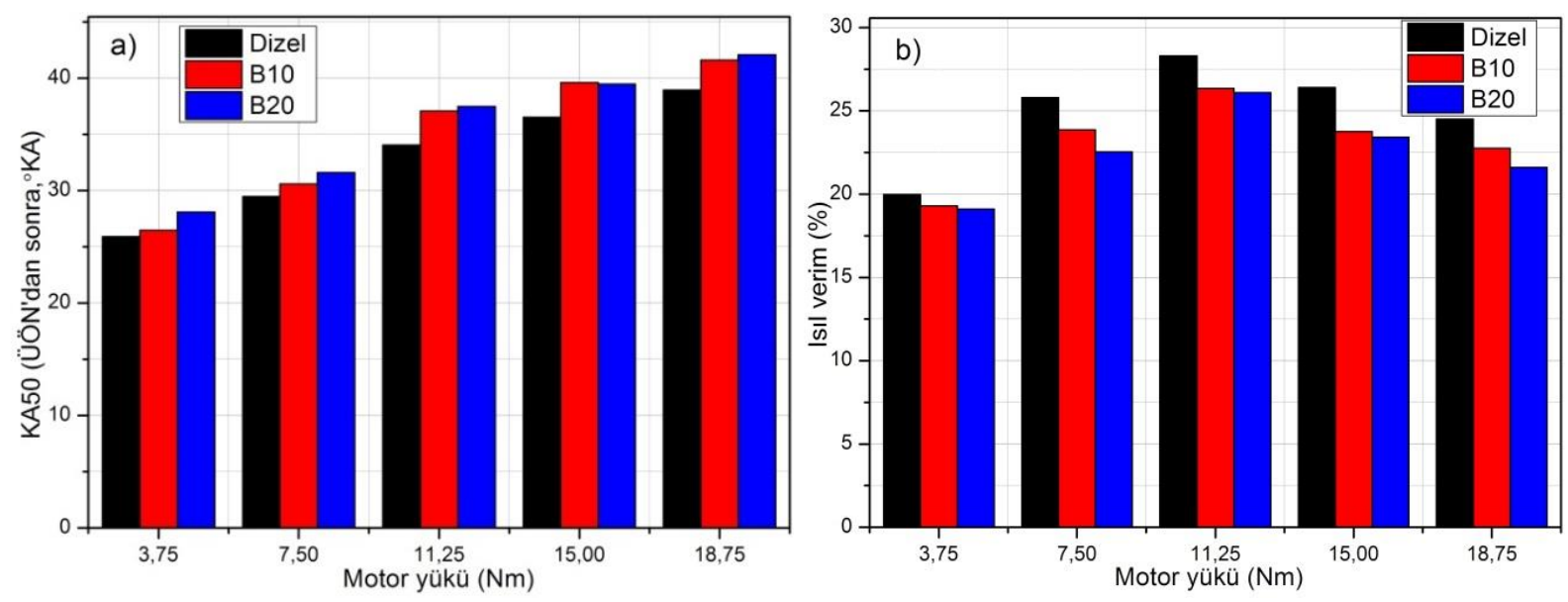

Şekil 8. KA50 ve isll verim

Şekil 9-a'da motor yüküne bağlı CO emisyonunun değişimi görülmektedir. Dizel ile ölçülen CO tüm yüklerde karışım yakıtlardan fazladır. Yük arttıkça yanma odasında oksijen konsantrasyonu azaldığı için $\mathrm{CO}$ oluşumu artmaktadır. Tam yanma gerçekleşememekte $\mathrm{CO}$ açığa çıkmaktadır. Bunun yanında biyodizelin oksijen içermesi tam yanma işlemini iyileştirmekte ve yanma kalitesi artabilmektedir. Bunun sonucunda yeterli oksijeni bulabilen yakıt tutuşarak yanmasını tamamlayabilmektedir. Tam yükte (18.75 $\mathrm{Nm}) \mathrm{B} 10$ ve B20 yakıtı ile dizele göre $\mathrm{CO}$ sırasıyla \% 10,5 ve \% 17,6 azalmıştır. Şekil 9-b'de $\mathrm{CO}_{2}$ emisyonunun değişimi görülmektedir. $\mathrm{CO}_{2}$ benzer şekilde yük arttıkça tüm yakıtlar için artış göstermektedir. Fakat $\mathrm{CO}$ emisyonundan farklı olarak karışımdaki biyodizel miktarı arttı̆ğında $\mathrm{CO}_{2}$ artmaktadır. Motor yükünün artması yanma odasına sürülen ve oksidasyonu sağlanan yakıt miktarının ve silindir sıcaklığının artmasına neden olmaktadır. Yeterli sıcaklık ile yakıın yanmasını tamamlaması ve $\mathrm{CO}_{2}$ oluşumu görülmektedir. $18.75 \mathrm{Nm}$ motor yükünde $\mathrm{CO}$ dizel, $\mathrm{B} 10$ ve B20 yakıtı ile sirasıyla \%8,41, $\% 8,42$ ve \%8,49 ölçülmüştür. Şekil 10 -a'da $\mathrm{NO}_{\mathrm{x}}$ emisyonunun değişimi görülmektedir. Yüksek yanma sonu gaz sıcaklıklarında azot ve oksijen molekülleri reaksiyona girerek $\mathrm{NO}_{\mathrm{x}}$ emisyonlarını açığa çıkarır [5, 9, 24-26]. Şekil 10-a incelendiğinde motor yükü arttıkça oksidasyon reaksiyonlarına katılan yakıt miktarı artmakta, yanma sonu gaz sıcaklığı yükselmektedir.
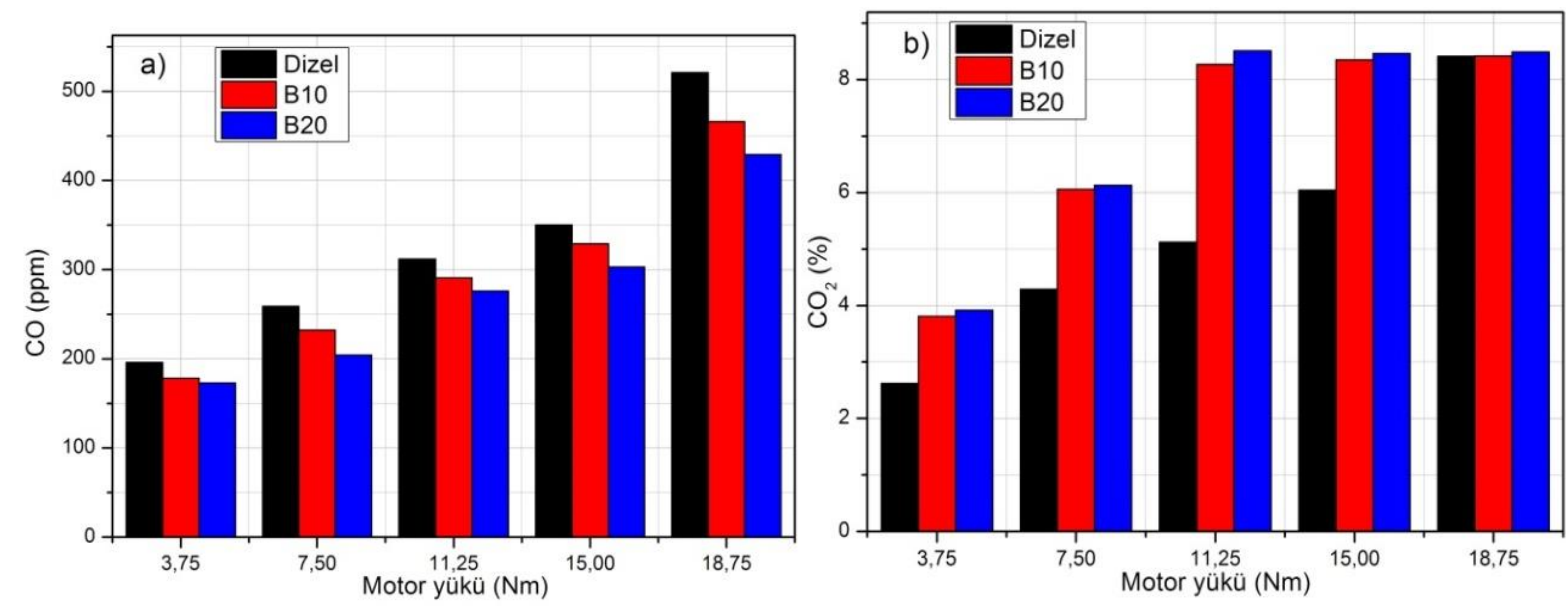

Şekil 9. $\mathrm{CO}$ ve $\mathrm{CO}_{2}$ emisyonlarının değiş̧imi

$\mathrm{NO}_{\mathrm{x}}$ yüksek yanma sonu gaz sıcaklıklarında meydana geldiğinden artmaktadır. Aynı zamanda her bir motor yükü için maksimum $\mathrm{NO}_{\mathrm{x}} \mathrm{B} 20$ ile ölçülmüştür. Biyodizelin yoğunluğunun ve oksijen içeriğinin fazla olması yanma sonu gaz sıcaklığının ve $\mathrm{NO}_{\mathrm{x}}$ emisyonlarının artmasına neden olmaktadır. Tam yükte 
B10 ve B20 ile dizele göre $\mathrm{NO}_{\mathrm{x}}$ sırasıyla \%1,5 ve \%7,5 artmıştır. Şekil 10-b'de motor yüküne bağl1 is emisyonlarının değişimi görülmektedir. Atık zeytinyağı biyodizelinin en önemli etkilerinden biri is emisyonları üzerindedir. Motor yükü arttıkça tüm yakıtlar için is oluşumu artmaktadır. Silindire sürülen yakıtın artması oksidasyon reaksiyonlarını kötüleştirmektedir. Bununla birlikte yanma odasında oksijen konsantrasyonunun azalması kısmi zengin karışım bölgelerinin oluşmasına ve is emisyonlarının açığa çıkmasına neden olmaktadır.
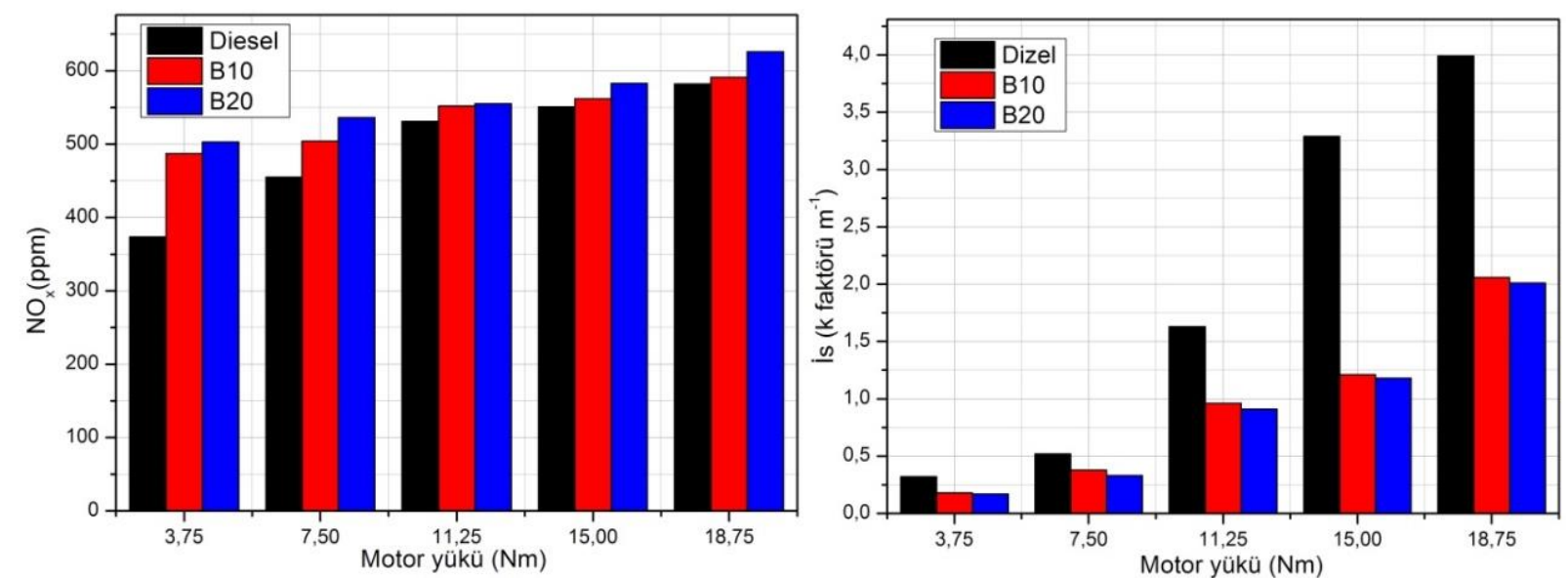

Şekil 10. a) $N O_{x}$ emisyonunun değiş̧imi b) İs emisyonunun değişimi

Ölçülen is emisyonları karşılaştırıldığında dizel ve karışım yakıtlar arasında büyük farkların olduğu görülmektedir. Tam yükte $(18,75 \mathrm{Nm}) \mathrm{B} 10$ ve B20 yakıtları ile dizele göre is emisyonları sırasıyla \%48,3 ve \%49,5 azalmıştır. Atık zeytinyağı biyodizelinin oksijen içermesi ve sülfür içeriğinin az olması is emisyonlarının azalmasına neden olmaktadır.

\section{SONUÇ (CONCLUSION)}

$\mathrm{Bu}$ çalışmada atık zeytinyağı biyodizelinin yanma, performans ve emisyon karakteristikleri üzerindeki etkileri deneysel olarak araştııılmıştır. Yakıt karışımlarının dizele yakın performans gösterdiği görülmüştür. Biyodizelin 1sıl enerjisinin düşük olması ve viskozite, yoğunluk değerlerinin yüksek olmas1 motor performansını azalmasına neden olmuştur. Tam yükte maksimum silindir basıncı ve 1sı dağılımının B20 yakıtı ile elde edildiği görülmüştür. Bu noktada yüksek motor yüklerinde biyodizel karışımları ile daha fazla silindir basıncı ölçülmüş̧ür. Biyodizel yakıt karışımları ile dizele göre tutuşma gecikmesi sürelerinin arttığı görülmüştür. Benzer şekilde motor yükü ve karışım yakıtlardaki biyodizel miktarı arttıkça yanma sürelerinin uzadığ görülmüştür.11,25 Nm motor yükünde ısıl verim B20 yakıtı ile dizele göre \% 7,8 azalmıştır. Tam yükte $\mathrm{NO}_{\mathrm{x}}$ emisyonları $\mathrm{B} 20$ ile dizele göre \% 7,5 artmıştır. Aynı yükte B20 ile CO ve is emisyonları dizele göre sırasıyla $\% 17,6$ ve $\% 49,5$ azalmıştır. Sonuçta atık zeytinyağ biyodizelinin dizel motorda herhangi bir değişikliğe gidilmeden verimli bir şekilde kullanılabileceği görülmüştür.

\section{KAYNAKLAR (REFERENCES)}

[1] M. Çelik, Combustion, performance and exhaust emission characteristics of organic based manganese addition to cotton methyl ester, Applied Thermal Engineering, 108, (2016) 1178-1189.

[2] E.,Büyükkaya, Effects of biodiesel on a DI diesel engine performance, emission and combustion characteristics, Fuel, 89, (2010) 3099-3105.

[3] P.,Verma, M.P., Sharma, Performance and Emission Characteristics of Biodiesel Fuelled Diesel Engines, International Journal Of Renewable Energy Research, 5, (2015) 1.

[4] İ.,Sugözü, F., Aksoy, Ş.A., Baydır, Bir Dizel Motorunda Ayçiçeği Metil Esteri Kullanımının Motor Performans ve Emisyonlarına Etkisi, Makina Teknolojileri Elektronik Dergisi, 6,2, (2009) 49-56. 
[5] F.,Aksoy, H.,Bayrakçeken, Ş.A.,Baydır, H.,Yavuz, Kanola YağıMetil Esterine Ön Isıtma Uygulamasının Motor Performans ve Emisyonlarına Etkisi, Taşıt Teknolojileri Elektronik Dergisi, $1,1,(2009)$ 25-33.

[6] S., Kaşifoğlu, M., Gümüş, C., Sayın, Palm Olein ve Soya Karışımı Bitkisel Yağın Metil Esterinin Dizel Motorlarında Alternatif Yakıt Olarak Kullanımı, 10. Uluslararası Yanma Sempozyumu, 504$511,2008$.

[7] E.,Ansari, K.,Poorghasemi, B.K., Irdmousa, M., Shahbakhti, M., J. D., Naber, Efficiency and Emissions Mapping of a Light Duty Diesel-Natural Gas Engine Operating in Conventional Diesel and RCCI Modes SAE Technical Paper, (2016) (No. 2016-01-2309).

[8] K.,Poorghasemi, R.K., Saray, E.,Ansari, B.K., Irdmousa, M.,Shahbakhti, J.D., Naber, Effect of diesel injection strategies on natural gas/diesel RCCI combustion characteristics in a light duty diesel engine, Applied Energy, 199, (2017) 430-446.

[9] A.,Uyumaz, H., Solmaz, E., Y1lmaz, H., Yamık, S., Polat, Experimental examination of the effects of military aviation fuel JP8 and biodiesel fuel blends on the engine performance, exhaust emissions and combustion in a direct injection engine, Fuel Processing Technology, 128, (2014)158-165.

[10] E.,Dobrucali, R.U., Ozcumal1, S., Ergin, The effect of biodiesel on exhaust emission characteristics of a diesel engine, Marit. Ind. Ocean Eng. Coast. Resour., 1, (2008) 345-350.

[11] M.,Çelik, H., Solmaz, H.S., Yücesu, Examination of the effects of organic based manganese fuel additive on combustion and engine performance, Fuel Processing Technology, 139, (2015) 100-107.

[12] N.,Yilmaz,TM., Sanchez, Analysis of operating a diesel engine on biodiesel-ethanol and biodieselmethanol blends, Energy, 46, (2012) 126-9.

[13]S.,Dixit, S.,Kanakraj, A.,Rehman, Linseed oil as a potential resource for bio-diesel: A review, Renewable and Sustainable Energy Reviews, 16, (2012) 4415-4421.

[14] D.,Agarwal, L., Kumarb, A.K., Agarwal, Performance evaluation of a vegetable oil fuelled compression ignition engine, Renewable Energy, 33, (2008) 1147-1156.

[15]A.M.,Ashraful, H.H., Masjuki, M.A., Kalam, I.M.R., Fattah, S., Imtenan, S.A., Shahir, H.M., Mobarak, Production and comparison of fuel properties, engine performance, and emission characteristics of biodiesel from various non-edible vegetable oils: A review, Energy Conversion and Management, 80, (2014) 202-228.

[16]A.,Demirbas, Production of biodiesel fuels from linseed oil using methanol and ethanol in noncatalytic SCF conditions, Biomass and Bioenergy, 33, (2009) 113-118.

[17]D.,Ashri, R., Kumar, Effective Process Parameters of Mustard Oil Biodiesel - A Review and Analysis, International Journal on Emerging Technologies, 5, 1, (2014) 99-106.

[18] R.,Behçet, S., Aydın, C., İlkılıç, H., Aydın, A.V., Çakmak, Atık Kızartma Yağı Metil Esterinin Bir Dizel Motorunda, Motor Performansı ve Egzoz Emisyonlarına Etkisinin Araştırılması, 6th International Advanced Technologies Symposium (IATS'11), 16-18 May 2011, Elazığ, Turkey.

[19]Ö.,Can, Combustion characteristics, performance and exhaust emissions of a diesel engine fueled with a waste cooking oil biodiesel mixture, Energy Conversion and Management, 87, (2014) 676686.

[20]Ö.,Can, E.,Öztürk, H., Solmaz, F., Aksoy, C., Çinar, H.S., Yücesu, Combined effects of soybean biodiesel fuel addition and EGR application on the combustion and exhaust emissions in a diesel engine, Applied Thermal Engineering, 95, (2016) 115-124. 
[21]D.,Agarwal, L., Kumarb, A.K., Agarwal, Performance evaluation of a vegetable oil fuelled compression ignition engine, Renewable Energy, 33, (2008) 1147-1156.

[22]RD.,Misra, MS., Murthy, Straight vegetable oils usage in a compression ignition engine:a review, Renewable and Sustainable Energy Reviews, 14, (2010) 3005-13.

[23]SP.,Singh, D., Singh, Biodiesel production through the use of different sources and characterization of oils and their esters as the substitute of diesel: a review, Renewable and Sustainable Energy Reviews, 14, (2010) 200-16.

[24]A.,Karmakar, S., Karmakar, S., Mukherjee, Properties of various plants and animals feedstocks for biodiesel production, Bioresource Technology, 101, (2010) 7201-10.

[25]M. R., Uddin, K., Ferdous, M.R., Uddin, M.R., Khan, M.A., Islam, Synthesis of Biodiesel from Waste Cooking Oil, Chemical Engineering and Science, 1, 2, (2013) 22-26.

[26] J.B.,Heywood, Internal Combustion Engines Fundamentals, McGraw-Hill, USA, 1988.

[27]R., Stone, Introduction to Internal Combustion Engines, 1999;Macmillan Press Ltd, ISBN 0-33374013- 0,Tesseraux, I.; Toxicoll, Lett., 2004, 149, 295-300. 